\title{
La nación pluricontinental: La entelequia colonial del Estado Novo (1930-1974)
}

\author{
Adolfo Cueto Rodríguez* \\ Doctorando de la Universidad Nacional de Educación a Distancia (UNED) \\ Investigador del Instituto de História Contemporânea-(IHC-FCSH/UNL)

\section{The «pluricontinental» nation: The Estado Novo's colonial unreality (1930-1974)}

\begin{abstract}
RESUMEN
Entre la aprobación del Acto Colonial el 8 julio de 1930 y la caída de la Dictadura en Portugal el 25 de abril de 1974 mediaron casi cuarenta y cuatro años. Durante ese tiempo el imperio luso maduró y vivió diferentes coyunturas internacionales, siempre bajo la tutela de un único régimen político en la Metrópoli. La longevidad del Estado Novo se ha querido explicar por su capacidad de adaptación y resistencia. Sin

embargo, fue precisamente en el plano colonial donde ese ejercicio de acomodación mostró con mayor virulencia sus limitaciones. Como antes habian hecho la Monarquía constitucional y la I ${ }^{a}$ República, el «salazarismo» también aplicó su doctrina política a la administración del ultramar. Pero

en su caso, la defensa férrea de la unidad imperial a través de los principios y canales

antidemocráticos que le eran propios, $y$ el hecho de hacerlo en un tiempo radicalmente diferente al de los regímenes que lo precedieron, condujo a su colapso y a la emancipación abrupta del Imperio, como es sabido. No obstante, hasta la llegada a ese desenlace, el Régimen no permaneció inmóvil frente a la Descolonización. Al seguimiento de la reflexión en torno a lo que
\end{abstract}

\begin{abstract}
Nearly forty four years have passed between the approval of the Colonial Act, on the 8th July 1930, and the fall of the Dictatorship in Portugal, on the 25th April 1974. During that time, the Portuguese Empire has matured and lived through different international contexts, always under the rule of a unique regime of the Metrópole. The duration of the Estado Novo is partly explained by its capacity to adjust and endure. However, it was precisely in the colonial context that this «exercise of adjustment» most experienced its limits. The same way the Monarchy and the Republic had done before, Salazar's regime applied its political doctrine to colonial administration. But in this case, the defense for imperial unity, which was carried out by using the regime's anti-democratic means and principles, and the changing context led to the fall and lost of its colonies, as it is well known. Nevertheless, and until the end, the regime didn't remain unmoved in face of decolonization. The following text is therefore dedicated to what was then the thought on how these
\end{abstract}

* Este trabajo de investigación ha podido realizarse gracias a la financiación del Programa Nacional de Becas para la Formación de Profesorado Universitario (FPU) del Ministerio de Educación de España. 
debían y podían ser las relaciones Metrópoli-Ultramar, y al esbozo de lo que fueron las «correcciones» políticoadministrativas consubstanciales, será a lo que dedicaremos el texto que sigue.

\section{PALABRAS CLAVE}

Imperio Portugués, Estado Novo, Política Colonial, Administración Colonial, Descolonización.

\begin{abstract}
«Mainland-Overseas» relations should be and to the analysis of politicaladministrative reforms that were approved by the Estado Novo regarding colonial matters.
\end{abstract}

\section{KEY WORDS}

Portuguese Empire, Estado Novo, Colonial policy, Colonial administration, Decolonization.

No resulta fácil definir qué significaba el Imperio para Portugal, y sin duda este no es lugar para desgranar la serie de consideraciones políticas, económicas, geoestratégicas, históricas y sociológicas que le dieron forma y valor. Sin embargo, lo que sí debemos reconocer es que la importancia que se le atribuyó fue intemporal -y por ello compartida por todos los regímenes a los que les cupo su gobierno-y transversal, en el sentido de que afectó hondamente a la vida política del país.

De hecho, en lo que dice respecto a los que debían ser los principios rectores de la política colonial portuguesa, la discusión giró siempre en torno a los mismos problemas: la pertenencia o no del agregado ultramarino a la Nación; la forma en que aquellos territorios podrían participar en la soberanía nacional; un régimen de administración especial o la extensión del modelo metropolitano; descentralización administrativa o autonomía política; estatutos cívicos iguales o diferenciados para la población de origen europeo y los «indígenas»; una relación económica intercolonial y de éstas con la Metrópoli y el mundo paritaria o de subordinación; etc. Y como se comprenderá, esta era una «deliberación» compleja, en la que se confrontaban modelos políticos diferentes, soluciones administrativas diversas y concepciones contrapuestas de lo que debía ser el conglomerado imperial a largo plazo. Un debate que, para el periodo que aquí nos interesa, debía hacerse además respetando los «dogmas» fundacionales de un régimen nacionalista, colonialista, oligárquico y antidemocrático, y vehicularse a través de sus prácticas orgánicas, con todo lo que ello implicaba.

Pero tan importantes como las bases de esa discusión fueron las circunstancias y los «tiempos» derivados de ellas. Coyunturas que entre 1930 y 1974 resultaron de la conjunción aleatoria de al menos tres planos distintos, cada uno con sus dinámicas propias, pero en mayor o menor grado interconectados:

En primer lugar, el exterior, habida cuenta de que el caso imperial portugués estuvo subordinado, de principio a fin, al fenómeno global de expansión y reflujo colonial europeo en el que se insería, siendo cualquier condicionamiento inverso imposible. 
El segundo plano a considerar es el ultramarino, en importancia sincrónica a la maduración política de las colonias. Si bien es verdad que en los territorios mayores existía desde el primer tercio del siglo XX una conciencia política incipiente entre los colonos, éstos no consiguieron controlar el «Estado colonial» ni condicionar las directrices trazadas desde Lisboa ${ }^{1}$. Para que la consideración de ese vector se hiciese indispensable habría que esperar a la organización política de las comunidades negras -en la década de los cincuenta- y a que sus reivindicaciones condujesen a la lucha armada en los años sesenta.

Y en tercero lugar, la evolución de la Metrópoli y con ella del propio Régimen -en este último caso, en lo concerniente a sus equilibrios internos, sus compromisos y sus percepciones de la realidad interior y exterior-, que como no podía ser de otra manera, tendrían también sus repercusiones en Ultramar.

Esta matriz analítica nos permite distinguir cuatro periodos con alguna singularidad dentro del continuo estanovista, siendo esa la compartimentación que utilizaremos para organizar el texto. El primero va desde la aprobación del Acto CoIonial hasta el fin de la Segunda Guerra Mundial, y su singularidad deriva del contexto imperial en que se inscribió, previo al reflujo general post-bélico. El segundo se prolonga desde esta última fecha hasta 1960, y se caracteriza por la naturaleza de la amenaza a la que Portugal tuvo que hacer frente, en estos lustros fundamentalmente diplomática. El tercer periodo arranca con la rebelión angoleña de 1961 y llega hasta la «desaparición política» de Oliveira Salazar en 1968, siendo la guerra y la política de integración los elementos que le dan unicidad. Y el último es el coincidente con el consulado de Marcello Caetano (1968-1974) y su tentativa fallida de revitalizar el Régimen y de implantar un sistema autonómico en las colonias.

\section{EL ACTO COLONIAL. LOS PRINCIPIOS COLONIALES DEL RÉGIMEN}

El 8 de julio de 1930 se promulgaba el Acto Colonial con categoría de ley fundamental para las colonias, adelantándose casi tres años a la Carta Magna del Régimen. Las razones de esa celeridad se explicaban en el preámbulo del propio texto: la necesidad de corregir el sistema de descentralización administrativa y autonomía financiera implantado por la República, que habrían fragilizado la soberanía nacional; y la intención de blindar —al menos legal y presuntamente - la integridad del Imperio frente a las ambiciones de otras potencias².

Hay que tener presente que hasta la Segunda Guerra Mundial, el mundo continuaba viviendo en un orden policéntrico y que el cierre en falso de la Gran Guerra no había hecho más que animar los últimos coletazos del revisionismo colonial.

\footnotetext{
1 Ver: PIMENTA, Fernando: Angola, os brancos e a independência. Porto, Afrontamento, 2008, pág. 130.

2 Decreto-Lei 18.570 «Acto Colonial» de 8 de julio de 1930.
} 
Y en ese contexto, el «patrimonio» ultramarino de Portugal apareció siempre como un blanco propicio para cualquier compensación ${ }^{3}$. Así, el miedo a una intromisión exterior avivada por los problemas financieros de las colonias mayores a mediados de los años veinte, los boatos autonomistas de los colonos de Angola en 1924 - que en Lisboa se interpretaron exageradamente como un conato independentista ${ }^{4}$ - y las críticas vertidas en 1925 por el informe de Edward Ross sobre el trabajo indígena en el África portuguesa, no hicieron más que dar argumentos a los golpistas - ya conjurados contra la República - para corregir el rumbo, también en éste ámbito.

En esencia, eran los mismos riesgos que el régimen republicano había intentado atajar unos años antes, en aquel entonces apostando por un modelo de dominio «compatible» con los principios del derecho colonial en vigor - promoción socio-política y económica de los territorios coloniales ${ }^{5}$. De ahí las leyes que regirían el gobierno civil y financiero de las colonias de 1914 y los estatutos de la mayoría de los territorios aprobados en 1917, que pasaban a dar contenido al precepto constitucional que reconocía el «predominio do regime de descentralização administrativa» y la autonomía financiera ${ }^{6}$. Un proceso, que alcanzaría su mayor expresión con la implantación en Angola y Mozambique del régimen temporal de Altos Comissários en 1920?.

Lo que había cambiado apenas un lustro después eran las circunstancias descritas y con ellas los detentores del Poder - los militares y una «derecha» política heterogénea, convergentes en el Golpe de Estado de1926- y la «filosofía» política y colonial dominantes ${ }^{8}$.

Así pues, con el golpe de 28 de mayo de 1926 se abría un proceso de revisión colonial que encontraría su corolario en el Acto Colonial cuatro años más tarde. Sus señas de identidad serían: centralización administrativa; austeridad financiera; dependencia económica; «nacionalización» de los recursos y de los espacios - grandes extensiones territoriales estaban bajo la administración de compañías mayestáticas-; y tipificación del distingo entre indígenas y ciudadanos.

Como cabía esperar, el Decreto de 1930 no estuvo exento de críticas, pues no era inocuo. Así lo demuestra la discusión acalorada vivida en la prensa y las obje-

${ }^{3}$ Durante las décadas de los veinte y treinta, las reivindicaciones más o menos formales de potencias como Italia, Alemania, Sudáfrica y hasta Polonia fueron normales. Ver: Arquivo Oliveira Salazar (AOS)/ Correspondência Oficial (CO) / Ultramar (UL) - 12.

4 ALEXANDRE, Valentim: Velho Brasil, novas Áfricas: Portugal e o Império (1808-1975). Porto, Afrontamento, 2000, págs. 201.

5 Ver: PROENÇA, M. Cândida: A questão colonial no parlamento, vol. Il (1910-1926). Lisboa, Assembleia da República - Dom Quixote, 2008, págs. 11-78.

6 Leyes 277 y 278 «Da Administração Civil das Províncias Ultramarinas» y «Da Administração Financeira das Províncias Ultramarina» respectivamente, de 15 de agosto de 1914.

7 Lei 1.005 «Do Regime Temporal de Altos Comissários» de 7 de agosto de 1920. Y Lei 1.022 «Regulamento do funcionamento dos Conselhos Legislativos» de 20 de agosto de 1920.

8 ALEXANDRE,Valentim: Ob. Cit., págs. 187 y 205-208. 
ciones hechas en el III Congrésso Colonial Nacional ${ }^{9}$. Sin embargo, y a pesar de la complejidad del asunto, la mayor controversia giró en torno al uso de los términos «Colonias» e «Imperio Colonial» en vez de los tradicionales «Provincias Ultramarinas» y «Ultramar», algo que sólo se comprende si tenemos presente que esos sustantivos debían sintetizar una filosofía colonial y una idea de imperio, y pasar por ser la sublimación de una política colonial de continuidad histórica. Así, si para algunos las alteraciones propuestas aproximaba el modelo luso al del resto de naciones imperiales e introducía un distingo entre Imperio y Metrópoli inconveniente y peligroso, para otros — ligados a la oposición-, la inconveniencia de la reforma iba más allá, subrayando que al contrario de lo que dictaba la letra del texto, la nueva legislación "desnacionalizaba» las colonias y las reducía a simples «propiedades» puestas al servicio de un puñado de intereses metropolitanos ${ }^{10}$.

Formalmente el Acto Colonial continuaba reconociendo la descentralización administrativa. Pero en realidad, no hacía más que profundizar en el camino ya apuntado por las Bases Orgánicas da Administração Colonial de $1926^{11}$, eliminando, ahora sí, los Altos-Comisarios -figura que desde 1920 acumulaba amplios poderes ejecutivos y legislativos propios del Gobierno central- y dejando como máxima autoridad en cada territorio a unos Governadores competencialmente mermados en beneficio del Ministério das Colónias ${ }^{12}$.

Las referidas Bases de 1926 también habían revisado los órganos que acompañaban a los Gobernadores. Esa normativa había fundido los consejos Executivo -funciones consultivas - y Legislativo - con competencias legislativas compartidas- del régimen republicano en uno solo, el Conselho de Governo, ahora apenas con funciones consultivas y deliberativas. $Y$ de la misma regulación se heredaba la suspensión del «régimen municipal» en aquellas áreas donde «a pessar de um longo regime de assimilação, ainda não conseguiu criar raízes», y que si antes ya tenía una aplicación parcial, desde la Carta Orgânica do Imperio Colonial Português de $1933^{13}$ la tendría aun menor, pues esa «aptitud» pasaba a depender del número de europeos residentes en la circunscripción ${ }^{14}$.

9 Ver: III Congresso Colonial Nacional - Actas das Sessões e Teses. Lisboa, Sociedade de Geografia, 1934.

${ }^{10}$ Carta de Bernardino Machado: "O Acto Colonial da Dictadura». Agosto de 1930. AOS/CO/U-1, págs. 264-275.

11 Decreto 12.421 «Bases Orgânicas da Administração Colonial» de 2 de octubre de 1926.

12 La Lei 1.005 de 7 de agosto de 1920, creaba la figura «temporal» de los Altos Comisarios y les atribuía competencias propias del Ejecutivo central. Esta desconcentración fue revertida apenas cuatro meses después del Golpe de Estado de mayo de 1926. Con la aprobación Acto Colonial, no sólo se suprimía la figura del Alto Comisario, sino que también pasaba a prohibir que las competencias privativas del Ejecutivo central fuesen ejercidas por un poder territorial inferior.

${ }^{13}$ Decreto-Lei 23.228 "Carta Orgânica do Império Colonial Português» de 15 de noviembre de 1933.

${ }^{14}$ La Lei 277 de 1914, compilada junto a otras disposiciones en el Decreto 7.008 de 20 de agosto de 1920, interpretaban la aplicación del régimen municipal desde una perspectiva extensiva y progresiva, ponderando en primer lugar la importancia de la comunidad blanca, pero abriéndola a comunidades nativas "com um grau especial de instrução e progresso" no necesariamente asimiladas. Frente a ello la interpretación de la regulación de 1926 era mucho más restrictiva. 
En relación a la «autonomia financeira», el Art 26을 del Acto Colonial mantenía prácticamente la redacción de las leyes republicanas: «São garantidas às colónias (...) a autonomia financeira que sejam compatíveis com a Constituição Política da República [y] o seu estado de desenvolvimento (...)» pero sumándole un tercer condicionante: "os seus recursos próprios (...)», con lo que ya se hacía una guiño a la obligatoriedad del equilibrio presupuestario y al control de los gastos ordinarios. Y ya con mayor concisión:

«Art. $40^{\circ} \mathrm{O}$ orçamento geral da colónia depende de aprovação expressa do Ministro das Colónias (...)» ${ }^{15}$.

«Art. 47ํㅡ A autonomia financeira das colónias fica sujeita às restrições ocasionais que sejam indispensáveis por situações graves da sua Fazenda ou pelos perigos que estas possam envolver para a metrópole.»

Como se podrá comprender, la nueva regulación no hacía más que reforzar la verticalidad del ejercicio de la soberanía, concentrando poderes en el Ministerio de Ultramar, a lo que se habría que sumar el predominio de lógicas de "elección» indirecta en la composición de los Conselhos de Governo en la parte de los miembros que no lo eran innatamente o por nombramiento del Gobernador. Un déficit de representatividad que desde la ley electoral de 1934 también se dejaría sentir en la Assembleia Nacional —obviando, claro, la propia naturaleza antidemocrática del Régimen y de su Cámara-, pues al fijar la existencia de un único distrito electoral, la visibilidad ultramarina en el parlamento desaparecía entre el resto ${ }^{16}$.

En materia económica, el plan de acción conducía a la reedición de una suerte de «Pacto Colonial» y a la «nacionalización» de los recursos y de los espacios coloniales. En relación a lo primero, los instrumentos más efectivos fueron -además de la convencional subida de las barreras arancelarias, no exclusiva del imperio portugués en estos años-, los Fundos Cambias de Angola (1931) y de Mozambique (1932), a través de los cuales se priorizaba la disponibilidad de liquidez para los pagos de las compras hechas a Portugal, y la extensión del régimen de Condicionamento Industrial al Ultramar (1936), que impedía la instalación de cualquier unidad fabril en las colonias sin la autorización expresa del Gobierno central, lo que a la postre significaría la fijación de un tejido económico típicamente dependiente y subordinado a los intereses metropolitanos ${ }^{17}$.

15 Por contra, en la Base $80^{a}$ del Decreto 7.008 de 1920 podía leerse: «A acção do Governo da República sobre o orçamento da colónia exerce-se pela verificação e correcção do cômputo das receitas, e pela verificação da legalidade das despesas inscritas, evitando, quanto possível, impedir ou frustrar a iniciativa dos governos coloniais, e de modo nenhum invadindo a esfera da competência deliberativa desses governos».

16 Decreto-Lei 24.631 de 6 de novembro de 1934

17 Decreto 19.773 de 27 de mayo de 1931 por el que se crea el Fundo Cambial da Província de Angola; Decreto 21.154 de 23 de abril de 1932 que crea el Fundo Cambial da Província de Moçambique; y Decreto 26.509 de 11 de abril de 1936 por el que se hace extensivo el régimen de Condicionamento Industrial a Ultramar. 
En lo que se refiere a la voluntad de reintegración completa en la «soberanía nacional» de aquellos espacios sujetos a la administración de compañías mayestáticas, en el Acto Colonial se pasaban a prohibir expresamente ese tipo de «alienaciones" y en su Art. $12^{\circ}$ se determinaba que las concesiones vigentes:

a) Não poderão ser prorrogadas ou renovadas no todo ou em parte;

b) O Estado exercerá o seu direito de rescisão ou resgate, nos termos das leis ou contratos aplicáveis;

c) O Estado terá em vista completa unificação administrativa da colónia.

Para terminar, no queremos dejar de hacer referencia a la manutención del distingo legal entre «ciudadanos» e «indígenas» por lo que dice respecto a la noción de «nación» y sus implicaciones en términos políticos ${ }^{18}$. No obstante, no nos extenderemos aquí más, puesto que en aquellos años esta tipificación ni rompía con el pasado ni con las prácticas normales en otros imperios ${ }^{19}$.

\section{LA REFORMA CONSTITUCIONAL DE 1951: LA INTEGRACIÓN TENDENCIAL Y SUS LÍMITES}

El final de la Guerra en 1945 trajo la degradación internacional de las potencias europeas, y de ello eran pruebas fehacientes el orden bipolar naciente y el proceso de emancipación de los pueblos dominados que ganaba fuerza. El compromiso de las dos superpotencias con la descolonización de los Territorio No Autónomos (TNA); el apoyo mutuo de los movimientos de liberación —bien patente en la Conferencia de Bandung de 1955-, y la ineficacia de los «ejercicios de resistencia» —administrativa, política, diplomática, económica, armada, etc.— de las potencias coloniales, no hacía más que avisar del reflujo imperial inminente e irresistible.

Así pues, como en la primera posguerra mundial, el impulso que forzaba una nueva revisión de la política colonial portuguesa venía del exterior. Y aunque las condiciones «interiores» —en el sentido amplio del término, es decir, considerándose como sujeto el conglomerado imperial- no eran las mismas, el acto reflejo del Gobierno de Lisboa tendió, como antaño, a sublimar algunos «principios» presentes en los textos que regían a gobernanza ultramarina rechazando otros, lo que significó una apuesta por la «integración» —-tendencial, a nuestro modo de ver.

${ }^{18}$ Esta distinción ya se contemplaba en la legislación de la Monarquía y de la la República, y no era extraña a la mayoría de los imperios europeos contemporáneos. No obstante, la novedad ahora era la tipificación y la presencia en los textos fundamentales de dicha condición. Decreto12.533 «Estatuto Civil, Político e Criminal dos Indígenas de Angola e Moçambique» de 23 de octubre de 1926 y Decreto 16.199 «Código do Trabalho Indígena» de 6 de diciembre de 1928, heredados de la Dictadura Miliar a lo que el Acto Colonial sumaba todo su Título II.

19 Sobre esta distinción estatutaria, ver: SILVA, Ana Cristina Nogueira: Constitucionalismo e Império: A cidadania no ultramar português. Lisboa, Almedina, 2009. 
Aunque en estos años la amenaza descolonizadora estaba aun lejos de la parte substancial del «patrimonio colonial portugués» - es decir, la africana-, el proceso de emancipación en Asia puso a Lisboa en guardia. Y de la voluntad de mantener el dominio directo sobre las colonias deduciría el Régimen su propia estrategia de resistencia. Esta debía ser integral —o lo que es lo mismo, dogmática- argumental, legal y territorialmente hablando, y eso se traducía en el rechazo frontal de cualquier gesto que pudiese sentar un precedente que arrojase dudas sobre el orden constitucional unitario -ahora y siempre, baluarte único al que cabría encomendar la defensa de las colonias en los foros mundiales. Y en lo inmediato, esta actitud obligaba al inmovilismo absoluto frente a cualquier reclamación sobre los enclaves de Oriente.

En lo que a nosotros nos interesa, la respuesta a la nueva situación se concretó en la substitución de la retórica imperial de los años treinta por la parte de ella que podía parecer más «virtuosa», empezando por recalcar la «singularidad» del hecho colonial portugués, la «unidad de destino» del conjunto y una interpretación de la nacionalidad «extensiva» —en un sentido esencialista y no político, claro-, para lo que el «lusotropicalismo» y la interpretación parcial de la legislación pretérita vinieron a dar el soporte necesario ${ }^{20}$.

En concomitancia con el nuevo "discurso", en 1951 se procedía a la depuración conceptual de la Constitución de 1933, pasándose a fijar expresamente en el horizonte la integración interterritorial como la meta a alcanzar ${ }^{21}$. De ahí que hayamos adjetivado estos esfuerzos de «tendenciales", puesto que en realidad, no eliminaba los distingos fundamentales que a todas luces ponían en entredicho la unicidad del Estado/Nación «pluricontinental» —o imperial, si se prefiere.

En 1945 ya se había acometido una pequeña reforma constitucional, siendo lo más substancia el aumento del número de diputados de la Assembleia Nacional de 90 a 120, de los que 13 -ahora sí- le correspondían al Ultramar ${ }^{22}$.

${ }^{20}$ El lusotropicalismo fue una teoría presentada en los años treinta por el sociólogo brasileño Gilberto Freira, en la que defendía la propensión de la colonización portuguesa a crear en los trópicos sociedades mestizas e integradas. Curiosamente, en aquellos años esa visión no tuvo buena acogida en Portugal. Por contra, ya en la década de los cincuenta, con las nuevas circunstancias internacionales y el cambio de las sensibilidades en lo relativo a la convivencia interétnica, dicha interpretación pasó, como se comprenderá, a ser útil a los propósitos políticos del Estado Novo en las Colonias y por eso ampliamente difundida en Portugal.

En cuanto la interpretación de los textos fundamentales de la administración ultramarina, se hizo en estos años al pie de la letra. Así, el precepto recogido en la Constitución de 1822 que definía la Nación como el agregado de todos los portugueses de ambos hemisferios y la ausencia durante mucho tiempo de referencias específicas al distingo entre indígenas y ciudadanos, llevó a deducir que la tradición lusa era la de integración interétnica, cuando en la realidad, en ningún caso se podría considerar parte de esa nación a otros individuos diferentes a las poblaciones de origen europeo que habitaban aquellas tierras, ni mucho menos que de facto el distingo entre blancos e indígenas no existiese en las normativas locales de cada colonia.

${ }^{21}$ Lei 2.048 Reforma constitucional de 11 de junio de 1951.

22 Lei 2.009 Reforma de la Constitución Política de la República Portuguesa de 17 de septiembre de 1945 y Decreto-Lei 34.938 de 22 de septiembre de 1945. 
La nueva revisión - tramitada de forma anticipada por la «urgencia» que había en remozar las partes relativas al ultramar, todo sea dicho de paso-, lo que hizo básicamente fue integrar el Acto Colonial en la Constitución como Título VII, eso sí, retirando aquellas nomenclaturas o expresiones que delatasen la subordinación colonial y que pusiesen en cuestión la manida unidad. De esa forma, el cambio más significativo fue la substitución de todas las referencias a "Colónia» e «Império» — cuya inclusión tanto había dado que hablar en 1930— por «Província Ultramarina» $\mathrm{y}$ «Ultramar» portugués.

Así, el Art. $2^{\circ}$ del Acto Colonial adoptaba la siguiente redacción como Art. 133ำ de la Constitución: «É da essência orgânica da Nação Portuguesa desempenhar a função histórica de colonizar as terras dos Descobrimentos sob sua soberania e de comunicar e difundir os benefícios da sua civilização (...)», suprimiéntose expresiones como: «possuir e colonizar domínios ultramarinos» y «civilizar as populações indígenas».

También dentro del Título VII, la referencia a la transitoriedad del estatuto del «indigenato», pasaba a inserirse en el Capítulo II - Das garantias gerais, atenuándo algo la estanquidad del antiguo Capítulo II - Dos indígenas, que como si de un cuerpo extraño se tratase, era el único canal a través del cual sus «beneficiarios» participaban de la Constitución. Y ya en las disposiciones del nuevo Capítulo III Das garantáis especiáis para os indígenas, se hacía más hincapié en la vocación «promocional» de dicha condición.

Pero a pesar de ser muy limitada, la reforma tampoco estuvo exenta de críticas:

«A Câmara [Corporativa] chama muito particularmente a atenção para os perigos de uma assimilação prematura dos territórios ultramarinos à Metrópole. As suas condições naturais são e permanecerão diferentes; diferentes, e muito, são também na maior parte deles as condições sociais e econômicas. Desta diferença, que salta aos olhos do mais desprevenido observador, resulta a necessidade da especialização do governo, da administração e das leis» ${ }^{23}$.

De facto, y en contra lo que ya habían hecho otros imperios coloniales, Portugal no suprimió el distingo entre ciudadanos e indígenas, o lo que es lo mismo, entre individuos con derechos políticos y sujetos a las leyes metropolitanas y los que carecían de ellos, se sometían al derecho consuetudinario y «participaban» en la administración a través de las instituciones tradicionales. Así, el Estatuto do Indigenato, en vigor desde 1929, fue renovado en $1954^{24}$.

Fue en el campo económico donde las rectificaciones acometidas reflejaron mejor la «vocación» integracionista. El nuevo texto pasaba a hacer referencia expresa al objetivo de crear un mercado de factores unido. Continuó utilizándose la

${ }^{23}$ Parecer 10/V da Câmara Corporativa de 19 de enero de 1951.

24 Decreto-Lei 39.666 «Estatuto dos Indígenas Portugueses das províncias da Guiné, Angola e Moçambique» de 20 de mayo de 1954. 
fórmula recogida en el Art. 5 del Acto Colonial: «O Imperio Colonial Português [ahora con la fórmula "as Províncias Ultramarinas"] é [são] solidadrio[as] nas suas partes componentes e com a metrópole», que significaba a fin de cuentas la «subordinación» de las primeras a la segunda. Sin embargo y a diferencia de la normativa reducida que el Acto Colonia prestaba a este campo — se ocupaba más de la vertiente financiera, fruto de las circunstancias en las que había nacido- en el nuevo Capítulo V - Da orden económica, se podía leer:

«Art. $158^{\circ} \mathrm{A}$ organização econômica do ultramar deve integrar-se na organização econômica geral da Nação portuguesa e comparticipar por seu intermédio na economia mundial.

Único. Para atingir os fins indicados neste artigo facilitar-se-á pelos meios convenientes, incluída a gradual reducção ou suspensão dos direitos aduaneiros, a livre circulação dos produtos dentro de todo o território nacional. O mesmo princípio se aplicará quando possível à circulação das pessoas e dos capitais.»

Esas directrices fueron adquiriendo cuerpo con la regulación subsidiaria sobre movilidad y asentamiento de ciudadanos en Ultramar aprobada en 1956 y con la supresión de los derechos de importación, exportación y otros gravámenes aplicados a las mercancías originarias o nacionalizadas en una colonia para entrar en otra de $1957^{25}$.

En este dominio tampoco queremos dejar de mencionar que a lo largo de la década - y después-, no dejaron de crearse comisiones de estudio y planificación sectoriales y territoriales con la intención de identificar los recursos coloniales para su explotación. Un esfuerzo que acompañaría la política de planificación de inversiones a largo plazo y la cooperación regional impulsada en conferencias internacionales sectoriales en las que Portugal pasó a estar presente junto a otras «potencias administradoras». En definitiva, medidas que seguían las acciones de otras metrópolis, pero que en el caso de Portugal, en lugar de interpretarse como preparatorias para el futuro "autogobierno», serían sí, una demostración de su compromiso con la permanencia.

La línea integracionista aún tendría dos ocasiones más para expresarse. La primera a través de la nueva Lei Orgânica do Ultramar de 1953, que introducía el siguiente presupuesto en el capítulo relativo a la administración de las «provincias ultramarinas»: «Quando as circunstancias o aconselharem, poderá instituir-se no respectivo estatuto um regime de administração semelhante ao das Ilhas Adjacentes», Azores y Madeira, que eran de facto parte integrante de la Metrópoli ${ }^{26}$.

La segunda ocasión vino con la «corrección» constitucional de 1959 —esta vez provocada por la desestabilización del Régimen el año anterior. De ella, lo que

${ }^{25}$ Decreto-Lei 40.610 de 25 de mayo de 1956 y Decreto-Lei 41.026 de 9 de marzo de 1957, respectivamente.

${ }^{26}$ Lei 2.066 «Lei Orgânica do Ultramar Português» de 27 de junio de 1953. 
más nos interesa es el Art. 134으, que repitiendo que el régimen general de gobierno de las provincias ultramarinas sería el que mejor se adecuase a sus condiciones especiales (geográficas y sociales), se le agregaba: «A organização políticoadministrativa deverá tender para a integração dos outros territórios nacionais» ${ }^{27}$.

Con estas correcciones, los sectores más conservadores del Régimen pasaron a ver la Carta Magna como «texto programático» en materia colonial, y como se podrá imaginar, las repercusiones de esa apalancamiento del núcleo dura iba a suponer un problema insalvable cuando en el futuro, la problemática colonial se complicase y requiriese respuestas maleables.

\section{LA GUERRA COLONIAL Y LAS CONTRADICCIONES DE LA TEORÍA Y LA PRÁCTICA}

Con la nueva década el expediente colonial portugués entró en una nueva fase. En diciembre de 1960 la Resolución 1542 de la Asamblea de las Naciones Unidas catalogaba todas las posesiones ultramarinas de Portugal como Territorios No Autónomos (TNA), lo que significaba que si por una parte no aceptaba la validez de la «unicidad» recogida en el ordenamiento constitucional luso, por la otra reconocía a las colonias el derecho a la autodeterminación tal y como rezaba la Resolución 1514 (XV). En ese mismo año se asistía a la mayor ola de independencias de la historia — casi todas de países del África Subsahariana, de lo que se deducía que no cabrían dudas sobre cuál era la posición del los antiguos dueños del mundo respecto a la Descolonización, y que en adelante, las posesiones portuguesas tendrían por vecinos a los nuevos estados independientes y hostiles. $Y$ de ese «crecimiento» del número de estados no cabía esperar otra cosa que la extensión a nivel global de la competición creciente entre los EEUU y la URSS por atraerlos a sus orbitas respectivas. Todo sumado, junto a la madurez de los movimientos de liberación de las posesiones lusas, creó el caldo de cultivo perfecto para que el problema ultramarino luso diese un salto cualitativo. Y ese extremo se concretó el 15 de marzo de 1961 con el inicio de la lucha por la emancipación en el norte de Angola, situación a la que se sumó Guinea en 1963 y apenas un año después también Mozambique.

Pero antes de que el país pasase a convivir «cotidianamente» con el conflicto, la perspectiva de tener que afrontar una guerra subversiva - vistas las lecciones de Indonesia, Indochina y Argelia - para la que las Fuerzas Armadas portuguesas no estarían preparadas, y el hecho de tener que hacerlo sin el apoyo explícito de los aliados naturales, empujó a una parte de la cúpula militar a protagonizar una tentativa de golpe de Estado contra Oliveira Salazar y su política colonial, apenas un mes después de iniciada la insurrección en Angola. Con todo, si esas mismas circunstancias no hicieron al Gobierno renunciar a su compromiso de resistencia

27 Lei 2.100 Revisión constitucional de 29 de agosto de 1959. 
- podría decirse que en el caso del golpe fallido del 13 de Abril, hasta lo reforzó por la depuración de la cúpula militar que le siguió-, sí que provocaron un nuevo proceso de reflexión y rectificación.

La respuesta que iría a dar el Estado Novo terminó por organizarse en torno a cuatro líneas de acción: represión armada del independentismo; refuerzo de la cohesión interna en trono la defensa de la «Patria» amenazada en su parte extraeuropea; intensificación de las acciones diplomáticas sobre las potencias occidentales valiéndose del presupuesto simplista de que el «problema» angoleño se reducía a un episodio más de la lucha de bloques; y un nuevo proceso de revisión del ordenamiento colonial vigente ${ }^{28}$.

En relación a éste último aspecto, que es el que aquí nos interesa, decir que las reacciones no se hicieron esperar. El mismo día que se malograba la asonada Adriano Moreira era nombrado ministro de Ultramar, con el difícil encargo de aproximar la realidad del Imperio Portugués a la teoría.

No desgranaremos toda la batería de medidas adoptadas durante su «ministerio» por razones de espacio y por su diversidad, pero sí haremos referencia a lo más relevante. Y sin duda, la revocación del Estatuto dos Indígenas el 6 de septiembre de 1961, fue una de las medidas más reseñables ${ }^{29}$. Las razones para ello venían impuestas por la presión internacional y por la necesidad de dar mayor consistencia a la pretensa unidad política, para cuya negación los críticos internacionales habían encontrado en la diferencia de estatutos políticos la evidencias incontestable de que las posesiones portuguesas estaban sometidas a un régimen colonial ${ }^{30}$.

Sin embargo, el carácter circunstancial de la derogación parece traslucirse en las palabras pronunciadas por el Presidente do Conselho pocos meses antes, cuando preguntado sobre cuánto tiempo más podría Portugal seguir negando la ciudadanía al 94\% de la población de Angola, respondía:

"Adivinha-se na pergunta o pressuposto de que o atributo de direitos de cidadania, só por si, resolveria todos os problemas. Mas esta solução apenas é váli-

\footnotetext{
28 Ver: CUETO RODRÍGUEZ, Adolfo: El mundo frente a Portugal y Portugal contra el mundo. El expediente colonial portugués y sus efectos sobre la posición internacional lusa (1951-1962). Cuadernos de Historia nำ 7. Madrid, CEHRI, 2010.

29 Sobre la condición de ciudadano y el Estatuto do Indigenato, ver: SILVA, Cristina Nogueira da: Ob. Cit. y CRUZ, Elizabeth Ceita Vera: O Estatuto do Indigenato (Angola). A legalização da discriminação na colonização portuguesa. Luanda, Chá de Caxinde, 2006.

30 Según la Resolución 1541 (XV), de 15 de diciembre de 1960, eran definitorias del estatuto de TNA Ob. Cit. aquellas condiciones políticas, administrativas, jurídicas e históricas que implicasen una subordinación arbitraria del territorio en cuestión a la Metrópoli. De la misma manera, un territorios dominado sólo podía dejar de serlo: tornándose independiente; a través de una libre asociación; o integrándose en un Estado ya constituido [siendo este el caso pretendido por Portugal]. Y para que este último caso fuese válido, la unión debía hacerse sobre la en plena igualdad, y reconociéndose a los viejos y nuevos integrantes el mismo estatuto de ciudadanía, los mismos derechos y las mismas posibilidades de representación y participación en los órganos ejecutivos, legislativos y judiciales del gobierno, en todos sus grados.
} 
da nos casos em que tais direitos possam ser efetivamente exercidos e em que, a par dos privilégios que garantem, exista a perfeita noção das responsabilidades e deveres que impõem, [la concesión automática de la ciudadanía plena sería] um subterfúgio para dar satisfação a quantos se contentam com aparências. (...) Um decreto a reconhecer a cidadania faz-se em minutos e pode fazer-se já: um cidadão, isto é, o homem plena e conscientemente integrado numa sociedade política civilizada, leva séculos a fazer» ${ }^{31}$.

Y a esa misma deducción se podría llegar si se tiene presente que el mismo día que se aprobaba la referida derogación, se promulgaba también otros decretos que garantizaban la manutención de algunas peculiaridades contempladas en el Estatuto. Tal era el caso de las Regedorías (organismos de administración local tradicional), del sometimiento voluntario de los «ex indígenas» al derecho consuetudinario o al portugués y la perpetuación de la estructura judicial especial ${ }^{32}$. En este caso, se intuye también el utilitarismo de las medidas, porque si por un lado interesaba a Portugal continuar controlando las poblaciones «tribalizadas» a través de las estructuras tradicionales, por el otro tampoco querría generar rechazo hacia la administración colonial entre los mismos colectivos al suprimir algunas «peculiaridades» de su ordenamiento bien valoradas. Y más si tenemos presente que cualquier tensión en este ámbito sería aprovechada por los movimientos de liberación para extender la rebelión.

De todas formas, la simple equiparación que ahora se hacía en términos formales no significaba de facto la igualación de unos colectivos y otros a la hora de «participar en la administración» —y menos en la relación interétnica y económica-, pues de facto no todos tendrían derecho de voto como resultado de las muchas dificultades procesales que lo reducían normalmente y que en su caso aun serían peores - piénsese, por ejemplo, en la no inclusión en el censo.

Y acompañando la extensión de la «ciudadanía», solo dos días después se revisaba la ley electoral ${ }^{33}$. La nueva regulación reconocía a las «provincias ultramarinas» 23 escaños de los 130 que tenía la Assembleia desde la reforma constitucional de 1959. No obstante, y como señalábamos para periodos anteriores, esa representatividad continuaba estando condicionada por la propia naturaleza antidemocrática del Estado Novo, cabiéndole siempre esa función a los candidatos del partido del Régimen, que tendrían la «elección» garantizada.

Ya después de la caída en desgracia del ministro, se aprobaron la reforma de la Lei Orgânica do Ultramar ${ }^{34}$ y los estatutos de todas las «províncias». En este

${ }^{31}$ Entrevista concedida por Antonio de Oliveira Salazar a The New York Times, a mediados de 1961. En: Ultramar. Revista da comunidade portuguesa e da actualidade ultramarina internacional, $n^{\circ}=5$, julioseptiembre de 1961. Lisboa. Comissão Nacional da Mocidade Portuguesa, pág. 180.

32 Decreto 43.896 Regulación de la Regedorias, Decreto 43.897 sobre jurisprudencia tradicional (indígena) y Decreto 43.898 sobre el funcionamiento de los juzgados especiales, todos del 15 de septiembre de 1961.

33 Decreto-Lei 43.901 de 8 de septiembre de 1961.

34 Lei 2.119 «Lei Orgânica do Ultramar» de 24 de junio de 1963. 
ámbito, el tenor de la revisión propuesta por Adriano Moreira podría llevar a engaños si se atiende sólo a los adjetivos con los que pretendió delimitarla: «descentralização administrativa irreversível» y «desconcentração» aparentemente horizontal ${ }^{35}$. Y decimos que resulta engañosa porque, como veremos, los resultados fueron muy limitados.

Los gobernadores seguían siendo nombrados por el Gobierno central, y a pesar de ampliarse sus competencias, estas continuaban siendo restringidas. Y otro tanto sucedería con la referida desconcentración de competencias del Ministerio de Ultramar al resto -estos, con contadas excepciones, solo ejercían su actividad en la Metrópoli.

Sí que se produjeron algunas modificaciones en la organización de los gobiernos «provinciales» como por ejemplo la separación de los Conselhos de Governo (con competencias consultivas) de los Conselhos Legislativos, con funciones legislativas compartidas. A lo que hay que añadir que a pesar de las alteraciones acometidas, la representatividad de los segundos $-\mathrm{y}$ ni que decir tiene de los primeros- continuó siendo extremadamente reducida. A pesar de que se amplió el número de integrantes elegidos directamente por los ciudadanos inscritos en el censo, no se suprimieron los diputados nombrados ni tampoco las «lógicas» electorales indirectas, como se ve en los Estatutos.

En ese sentido, y tomando el ejemplo de Angola, continuó habiendo escaños reservados a la elección de los mayores contribuyentes de la "provincia», de las organizaciones religiosas, de las culturales, de las económicas y de las laborales, de las Regedorías y del propio aparato administrativo. De ese modo, si la regulación de $1955^{36}$ determinaba que de los 26 diputados que tenía la cámara, el 31\% lo fuesen por nombramiento, el $27 \%$ por elección de los cuerpos electorales especiales y el $42 \%$ por elección directa de los electores censados, con la reforma de 1963 la misma cámara, que pasaba a tener 36 diputados, contaba con un 5,6 \% que lo que lo eran por nombramiento, un $52,8 \%$ designados por cuerpos especiales y un $41,6 \%$ por elección directa ${ }^{37}$. Es decir, que fueron esos cuerpos electorales corporativos los que más se beneficiado de la reducción del número de escaños por nombramiento y del incremento del número total de miembros de la Cámara.

Lo que sí se recogió en la nueva Ley -en coherencia con la ya referida ampliación del número de diputados que le cabían al Ultramar en la Asamblea- fue el derecho de las «provincias ultramarinas» a nombrar representantes en la Câmara Corporativa y en todos los órganos consultivos de ámbito nacional -léase el Conselho Ultramarino, que funcionaba como cuerpo asesor del Ministro e instancia judicial superior de las colonias.

35 Comunicación hecha por Adriano Moreira en el Conselho Ultramarino el 22 de septiembre de 1962.

36 Decreto 40.225 «Estatuto Político-Administrativo da Província de Angola» de 5 de julio de 1955.

37 Decreto 43.374 «Estatuto Político-Administrativo da Província de Angola» de 22 de noviembre de 1963. 
Como cabía esperar, estas alteraciones fueron recibidas con frialdad por la comunidad internacional, pues no alteraban en lo substancial la realidad precedente y tampoco daban indicio alguno de un futuro cumplimiento de las obligaciones recogidas en las resoluciones. Y del otro lado de la trinchera lo único que estaban dispuestos a escuchar era una declaración de cese de las hostilidades y una propuesta de plazos para una independencia total.

Donde sí que se apostó con claridad por la integración interterritorial fue en el ámbito económico. A las directrices referidas en el apartado anterior, ahora se sumaba la aprobación en 1961 del llamado Espaço Económico Português $(E E P)^{38}$, que fijaba un plazo de diez años para la supresión total de las barreras arancelarias entre las colonias y la metrópoli. También se relajación las condiciones impuestas a la inversión extranjera, se rectificó el régimen de Condicionamiento Industrial y se intentó reproducir el modelo bancario metropolitano en ultramar. No obstante, el proceso de integración económica tendría que suspenderse meses antes del desarme total, previsto para enero de 1972, por los graves desequilibrios financieros ${ }^{39}$.

El interés de la economía metropolitana estaba en Europa, y aunque el imperio era un mercado importante, solo la vigencia temporal del EFTA permitió que África y el Viejo Continente no fuesen opciones excluyentes. Cuando la Europa de los Siete de disgregó, el interés del tejido económico portugués pasó a estar en la Comunidad Económica Europea, y esta sí que era una opción incompatible con el EEP y con el Régimen si el objetivo era la adhesión ${ }^{40}$.

\section{EL CALLEJÓN SIN SALIDA DE MARCELLO CAETANO: LA AUTONOMÍA NOMINAL Y EL PROBLEMA DE LA REPRESENTACIÓN POLÍTICA}

Una vez más, antes del desenlace que para el Imperio y el Régimen supuso el 25 de Abril de 1974, aun habría tiempo para un último intento de reforma colonial, ésta vez asociado a la tentativa fallida de revitalizar el sistema político.

Con la desaparición política de Oliveira Salazar en 1968, el Estado Novo perdía al padre y el líder indiscutible que había guiado los destinos en las últimas décadas. Y a pesar de que el traspaso de poderes se realizó sin sobresaltos - lo que no quiere decir que no provocase tensiones dentro de la cúpula estadonovista-, la herencia que dejaba a Marcello Caetano no sería fácil de gestionar ${ }^{41}$. Los cambios socio-económicos vividos en la Metrópoli en las últimas décadas auguraban reper-

\footnotetext{
38 Decreto-Lei 44.016 «Espaço Econômico Português» de 8 de noviembre de 1961.

39 Decreto-Lei 478/71 Revisión del «Sistema de Pagamentos Interterritoriais» y Decreto-Lei 481/71 sobre financiación de los «atrasados», ambos del 6 de noviembre de 1971.

40 TELO, José Antonio: «Portugal y la integración europea (1945-1974)». En: TORRE GÓMEZ, Hipólito de la (ed.): Portugal y España contemporáneos, Ayer, no 37. Madrid, Marcial Pons, 2000, págs. $287-318$.

41 Ver: CAETANO, Marcello: Depoimento. Rio de Janeiro, Record, 1975.
} 
cusiones para el entramado político. Pero la verdadera piedra de toque del consulado «marcelista» sería un expediente colonial en lento pero imparable deterioro.

De hecho, ambos problemas estaban intrínsecamente ligados. No podría haber reforma del Estado Novo sin terminar con la guerra en ultramar —que como insinuamos, condicionaba la agenda política al dividir al Régimen- y no sería posible resolver el problema ultramarino sin una reforma política que abriese el abanico de «soluciones» más allá de la resistencia sin fin seguida hasta la fecha.

En esas condiciones, el gobierno de Caetano entró en un callejón sin salida. La apertura política que esbozó en los primeros años de gobierno tan pronto desengañó a unos como provocó a otros, no pasando por eso mismo de ser un espejismo. En cuanto al problema ultramarino, el nuevo jefe del Gobierno ya se había comprometido a continuar con la política colonial de su predecesor antes de su nombramiento frente al Presidente de la República —una «obligación» para la que además la vigilancia amenazante del ala más reaccionaria del Régimen era un poderoso estimulante. En éste sentido, a pesar de sus antecedentes críticos con la política de integración, de haber propuesto una solución federalista en $1962^{42}$ y de reducir las razones de la resistencia a la defensa de los derechos de las poblaciones blancas y negras que sin la protección de Portugal sería entregadas a la «barbarie» "43, sus reformar no se salieron del guión marcado por la naturaleza del Régimen y sucumbieron al tiempo, que siempre había corrido contra Portugal.

La línea de acción definida por el Presidente hacía referencia a la «autonomia progresiva e participada», pero que en realidad no se sabe muy bien adónde quería llegar ${ }^{44}$. De hecho, el problema básico con el que se enfrentaba era el mismo de siempre, el déficit de representatividad del entramado político.

En 1971 se aprobaba la que sería la última reforma de la Constitución de $1933^{45}$, y lo más llamativo - aparte de la atribución a Angola y Mozambique el título «honorífico» de Estado-, era la reducción del articulado relativa al Ultramar — de cuarenta y tres artículos de 1951, se pasó a apenas cuatro—, en lo que parece una especie de «normalización» de los sujetos coloniales dentro de la cobertura general de la Carta Magna. Y en la misma línea de «resituación» del ultramar en el Estado, se volvió a ampliar el número de diputados de la Assembleia Nacional hasta los 150, correspondiéndole a las «Provincias ultramarinas» 34, lo que suponía una progresión del número de escaños en relación al total del 10,8\% en 1945 , al $17,6 \%$ en 1961 y hasta el $22,6 \%$ desde $1973^{46}$.

\footnotetext{
42 Ver: TORRE GÓMEZ, Hipólito de la y SÁNCHEZ CERVELLÓ, Josep: Portugal en la Edad Contemporánea (1807-2000). Historia y documentos. Madrid, UNED, 2000, págs. 459-461.

${ }^{43}$ Ver: Discurso de Marcello Caetano ante las Comissões Distritais da Acção Nacional Popular de 27 de septiembre de 1970.

44 Ver: Discursos de Marcello Caetano pronunciados ante los Conselhos Legislativo e Económico-Social de Mozambique, el 18 de abril de 1969, y ante la Assembleia Nacional el 2 de diciembre de 1971.

45 Lei 3/71 «Reforma da Constituição Política da República Portuguesa» de 16 de agosto de 1971.

46 Decreto-Lei 283/73 de 11 de junio de 1973.
} 
Con la nueva Lei Orgânica do Ultramar y los nuevos estatutos aprobados en 1972 se completaba la revisión de la gobernanza colonial ${ }^{47}$. Los gobernadores, como cabezas del poder ejecutivo eran referidos en el texto como «orgão de governo propio das provincias ultramarinas» pero continuaban siendo nombrados y depuestos por el Gobierno central, del que a fin de cuentas era representantes.

Las ahora llamadas Assembleias Legislativas, se compondrían en adelante solo de miembros elegidos. No obstante, las lógicas electorales especiales que referíamos en el apartado anterior, continuaban existiendo. Tomando como ejemplo los 53 vocales que componían la nueva cámara de Angola, 32 de ellos eran elegidos de forma directa por los votantes inscritos en los círculos electorales, lo que arrojaba una ratio de algo más del $60 \%$ de los representantes -era la primera vez que el número de diputados elegidos, y por elección directa, superaban el $50 \%$ de los miembros de la Cámara. Sin embargo, y a pesar de este avance, y si hacemos caso a lo que nos dice el que fuera Ministro de Ultramar en aquellos años, Joaquim da Silva Cunha, la elaboración del censo que debía elegir esos 32 escaños, se hizo atendiendo a criterios de "capacidad», lo que dejaba a la inmensa mayoría de la población sin voto — como siempre ${ }^{48}$.

En lo concerniente a la autonomía, si bien fueron ampliadas algunas prerrogativas de los poderes coloniales, en ningún caso el Gobierno central dejó de mantener los resortes fundamentales del poder. Constitucionalmente se continuaba garantizando que la «autonomía» no afectaba a la unidad del Estado, al Gobierno cabía la designación de los Gobernadores, las finanzas coloniales seguían sujetas a la fiscalización metropolitana, continuaba prohibida la contratación de préstamos en el extranjero, a Portugal cabía la responsabilidad de defender la integridad de la nacional, y la aprobación de los regímenes de gobierno de cada «provincia» era competencia del Ministerio de Ultramar.

La imposibilidad de legitimar el Estado colonial más allá de la noción descendente - y unitaria - de la soberanía «nacional» y de la «participação dos elementos estruturais da Nação na política e na administrasão geral e local» a través de los cauces ya referidos, serían un problema insalvable. Lo que a la postre nos lleva a deducir que esa «autonomía» «progresiva» y «participada», que podría inducir a pensar en modelo evolucionista de tipo británico, estaría pensada a priori para la comunidad euro-descendiente y en el mejor de los casos para los que de facto eran asimilados, siendo el horizonte probable una independencia blanca en las colonias mayores. Pero aun admitiéndose esa hipótesis, si esta reforma debía ser el punto de partida de esas propalada «progresividad», lo sería en un estadio extremadamente inicial.

47 Lei 5/72 «Lei Orgânica do Ultramar» de 23 de junio de 1972 y Decretos 541-547 Estatutos Político-Administrativos de las Provincias Ultramarinas, de 22 de diciembre de 1972.

48 CUNHA, Joaquim da Silva: O Ultramar, a nação e o 25 de Abril. Coimbra, Atlântida, 1977, pág. 285. 
En consecuencia, y como había sucedido en 1961, a estas alturas los pasos dados por el Gobierno de Lisboa en ningún caso se podían considerar una base válida para una negociación con los movimientos de liberación, todo lo contrario. Con la rebelión en expansión constante en Guinea y Mozambique y con mayores dificultades si cabe para recabar la ayuda material necesaria para mantener la guerra de los países occidentales, no resulta extraño que Marcello Caetano autorizase contactos no oficiales y secretos con los rebeldes, sin ningún horizonte concreto.

Cuando en 1974 la cúspide de las Fuerzas Armadas reconocían implícitamente la imposibilidad de ganar la guerra y apuntaban como única la salida política ${ }^{49}$, Caetano corrió en busca de la legitimidad donde no la había -al Presidente de la República y a la Asamblea Nacional-y de la fuerza a donde ya no estaba - a la cúpula militar, que ya había sido neutralizada por la subversión de la escala de mando hecha por el Movimiento de las Fuerzas Armadas. Para la mayor parte del tejido productivo portugués el futuro estaba en Europa, y para llegar a ella el expediente colonial era una rémora y el Régimen un inconveniente. Y otro tanto se podría decir del abandono progresivo de la Iglesia, palmario desde 1970. En esas condiciones, aislado en su propia incapacidad, el Gobierno terminó por caer entre la amenaza de la derecha y el golpe venido de las tropas de África cansadas y politizadas. El Imperio y el Régimen sucumbían a la vez el 25 de Abril de 1974.

\section{CONCLUSIONES}

La amenaza perpetua al patrimonio ultramarino portugués galvanizó la voluntad del país de ser «imperio», que fue asumida por la mayoría de las familias políticas. Y ese compromiso sobreviviría al Imperialismo, pero no a su reflujo.

Cuando la Descolonización se transformó en un fenómeno imparable, al Estado Novo, como «defensor» de algunos intereses económicos, sociales y políticos de la Metrópoli, le cupo rechazar el proceso, primero confiando en las garantías del derecho interno que negaba el hecho colonial, y después por la fuerza de las armas. Y en ese extremo, cuando a finales de la década de los sesenta las colonias pasaron de ser una "convicción" a un problema capital para la sociedad metropolitana, el destino del Régimen estaba sentenciado y con él de las colonias.

En esa carrera hacia el desastre, las reforma acometidas por el Régimen nunca desbordaron los límites impuestos por su naturaleza corporativa y antidemocrática. De ese modo, no pudiendo dar respuesta dentro de sus moldes políticos a las necesidades de cambio que se requerían en la Metrópoli y en Ultramar, terminó por vaciarse del «mandato» que antaño se había arrogado.

\footnotetext{
49 Ver: SPÍNOLA, António de: Portugal e o Futuro. Analise da conjuntura nacional. Lisboa, Arcádia, 1974.
} 
Cuando Marcello Caetano intentó corregir el rumbo era ya demasiado tarde, y el modo en el que pretendió hacerlo estaba condenado de antemano. La propuesta de «participación» en los asuntos públicos que hizo de la parte «cualificada» de la población colonial, tal vez habría podido servir antes de la organización política de las comunidades negras -y si los intereses metropolitanos a los que «representaba» el Régimen no se opusiesen, claro, pero no a esas alturas. Extremadamente embrionaria y reductora, en ningún caso podría poner fin al elemento central de la ecuación: la guerra. Por un lado, porque esos «herederos» del poder colonial no podrían resistir solos a las diferentes lógicas actuantes en el conflicto, y en segundo lugar, porque los movimientos de liberación no podrían admitir en ningún caso la propuesta como una base válida sobre la que negociar.

En esas condiciones, Estado Novo e Imperio estaban condenados a caer juntos.

\section{BIBLIOGRAFÍA}

ALEXANDRE, Valentim: A questão colonial no parlamento, vol. I (1821-1910). Lisboa, Assembleia da República - Dom Quixote, 2008.

ALEXANDRE, Valentim: Velho Brasil, novas Áfricas: Portugal e o Império (1808-1975). Porto, Afrontamento, 2000.

CAETANO, Marcello: Depoimento. Rio de Janeiro, Record, 1975.

CUETO RODRÍGUEZ, Adolfo: El mundo frente a Portugal y Portugal contra el mundo. El expediente colonial portugués y sus efectos sobre la posición internacional lusa (1951-1962). Cuadernos de Historia no 7. Madrid, CEHRI, 2010.

CUNHA, Joaquim da Silva: O Ultramar, a nação e o 25 de Abril. Coimbra, Atlântida, 1977, pág. 285.

DUARTE, A. E: «Salazar e a Política Colonial do Estado Novo». En: Salazar e o Salazarismo. Lisboa, Dom Quixote, 1989.

MACQUEEN, Norrie: The decolonization of Portuguese Africa: metropolitan revolution and the dissolution of empire. New York and London, Longman, 1997.

PIMENTA, Fernando Tavares: Angola, os brancos e a independência. Porto, Afrontamento, 2008.

PROENÇA, M. Cândida: A questão colonial no parlamento, vol. II (1910-1926). Lisboa, Assembleia da República - Dom Quixote, 2008.

ROSAS, Fernando y OLIVEIRA, Pedro A.: A transição falhada: O Marcelismo e o fim do Estado Novo (1968-1974). [Lisboa], Editorial Notícias, 2004.

SILVA, Ana Cristina Nogueira da: Constitucionalismo e Império. A cidadania no Ultramar português. Coimbra, Almedina, 2009.

SOUSA, Amélia Neves de: Caetano e o ocaso do «Império». Administração e guerra colonial em Moçambique durante o Marcelismo (1968-1974). Porto, Afrontamento, 2007.

SPÍNOLA, António de: Portugal e o Futuro. Analise da conjuntura nacional. Lisboa, Arcádia, 1974. TELO, José Antonio: «Portugal y la integración europea (1945-1974)». En: TORRE GÓMEZ, Hipólito de la (ed.): Portugal y España contemporáneos, Ayer, no 37. Madrid, Marcial Pons, 2000, págs. 287-318. 
TORRE GÓMEZ, Hipólito de la y SÁNCHEZ CERVELLÓ, Josep: Portugal en la Edad Contemporánea (1807-2000). Historia y documentos. Madrid, UNED, 2000.

TORRE GÓMEZ, Hipólito de la: «Marcello Caetano: últimas razones del Estado Novo». En: Espacio, Tiempo y Forma, Serie V, № 19, UNED, 2007, págs. 75-101.

- Portugal en el exterior (1807-1974). Intereses y política internacionales. Madrid, UNED, 2006. 